\title{
Multi-Domain Short Peptide Molecules for in Situ Synthesis and Biofunctionalization of Gold Nanoparticles for Integrin-Targeted Cell Uptake
}

\author{
Hilal Unal Gulsuner, ${ }^{\dagger}$ Hakan Ceylan, $^{\dagger}$ Mustafa O. Guler,* and Ayse B. Tekinay* \\ Institute of Materials Science and Nanotechnology, National Nanotechnology Research Center (UNAM), Bilkent University, 06800 \\ Ankara, Turkey
}

\section{Supporting Information}

ABSTRACT: We describe design and synthesis model of multidomain (modular) peptides (MDPs), which direct a reaction cascade coupling the synthesis and surface functionalization of gold nanoparticles (AuNPs) in a single step. The synthesis is achieved via simple mixing of the aqueous solutions of auric acid and MDPs at room temperature without the addition of any surfactants or toxic intermediate reagents. This method allows facile control over the nanoparticle size between $\sim 2-15 \mathrm{~nm}$, which opens a practical window for biomedical applications. In contrast to the conventional citrate-mediated methods, peptide-mediated synthesis and stabilization provide increased colloidal stability to AuNPs. As a proof of this concept, we demonstrate active targeting of human breast adenocarcinoma cell line (MCF7) using the one-step-prepared engineered AuNPs. Overall, we propose a single-step, chemically greener, biologically safer method for the synthesis and surface functionalization of gold nanoparticles in a sizecontrolled manner. The chemical versatility of the MDP design broadens the applicability of this strategy, thereby emerging as a successful alternative for the currently available nanoparticle preparation technologies.

KEYWORDS: gold nanoparticle, bioinspired synthesis, single-step nanoparticle preparation, targeted delivery

\section{INTRODUCTION}

Engineered gold nanoparticles (AuNPs) have drawn substantial attention due to their unique optoelectronic and physicochemical properties. Their exceptionally low cytotoxicity and high chemical stability in biological media have also enabled an extensive range of biomedical applications, such as drug or gene delivery, photothermal therapy, colorimetric sensing, and imaging. ${ }^{1-7}$ As targeting and delivery agents, application of engineered AuNPs have reached early phase clinical trials. ${ }^{8}$ As a result, preparation of AuNPs requires careful attention to controlling engineering parameters, such as size, shape, and surface coating, and purification of the final construct from toxic reactants.

Functionalized AuNPs are usually prepared by two successive reactions: In the first step, $\mathrm{Au}(\mathrm{III})$ ions are reduced into $\mathrm{Au}(0)$ by either citrate ions or sodium borohydride to synthesize nanoparticles in the range of $10-20 \mathrm{~nm}$ or $2-5 \mathrm{~nm}$, respectively. ${ }^{9-11}$ Alkanethiols, tetraoctylammonium bromide, cetyltrimethylammonium bromide, or Tween-20 are used as stabilizers for gold nanoparticles. In the second step, functional (bio) organic molecules containing a disulfide group are used to displace the intermediate stabilizer via a ligand exchange reaction. ${ }^{12}$ However, this method of preparing functionalized AuNPs has major drawbacks. For example, some portion of reacting AuNPs irreversibly fuse at the instantaneously destabilized sites to form larger aggregates during ligand exchange reaction. ${ }^{13}$ In addition, this reaction does not go to completion, which can significantly reduce functional ligand density on the nanoparticle surface, thereby reducing the expected effectiveness of the final construct. Moreover, toxic surfactants such as tetraoctylammonium bromide or cetyltrimethylammonium bromide are difficult to completely remove, and their desorption from the AuNP surface induces cell death. $^{14}$

Efforts to overcome such drawbacks have focused on developing novel chemical routes to prepare engineered AuNPs in facile and robust manners in a single step. One well-known approach of AuNP synthesis is reducing $\mathrm{Au}(\mathrm{III})$ ions to $\mathrm{Au}(0)$ using sodium borohydride in the presence of thiol-containing functional molecules, which cap the nanoparticle surface. ${ }^{15-17}$ Other studies used reductive hydroxyphenol derivatives for synthesis of AuNPs; however, they lack the ability to modulate their functional groups according to the desired application. ${ }^{18,19}$ Despite the progress, a practical method that couples the synthesis and biofunctionalization steps in one molecule in a chemically greener and biologically safer way is needed to significantly improve the usefulness of the nanoparticles, particularly in biomedical applications.

Received: September 17, 2014

Accepted: May 5, 2015

Published: May 5, 2015 
(a)
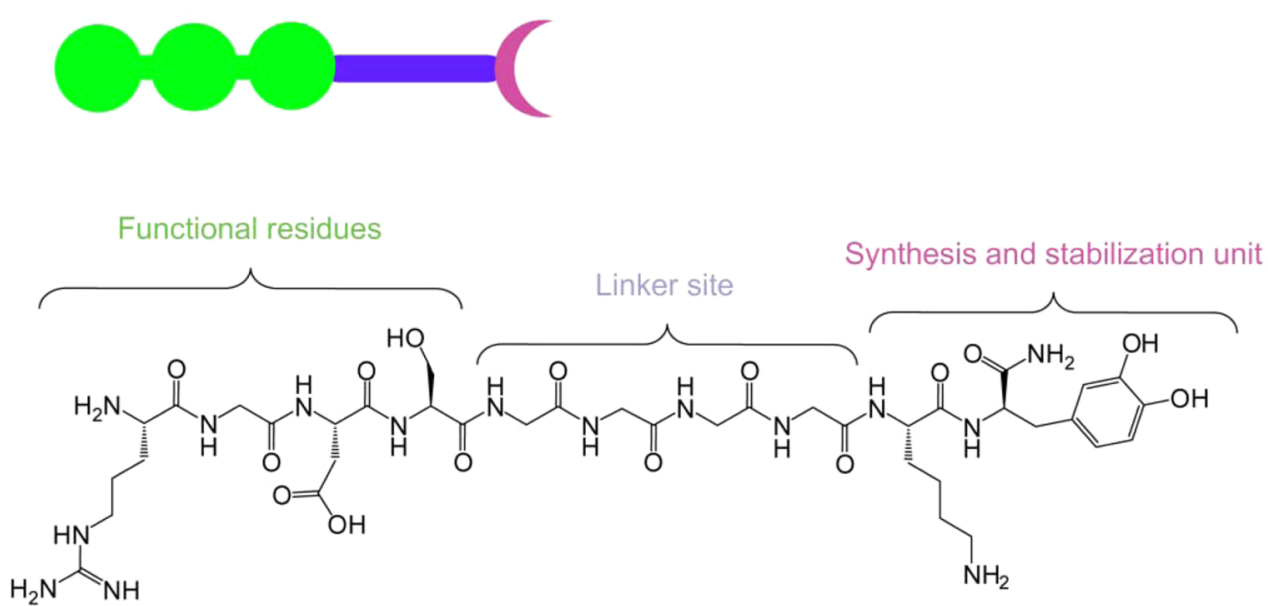

(b)

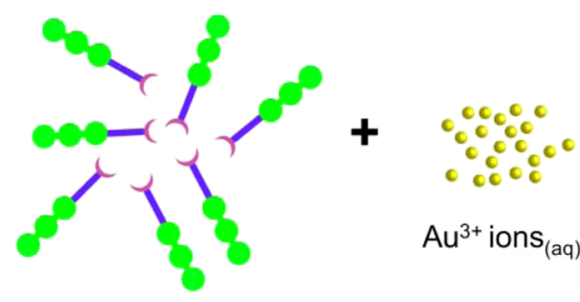

Multi-domain peptides $_{(a q)}$

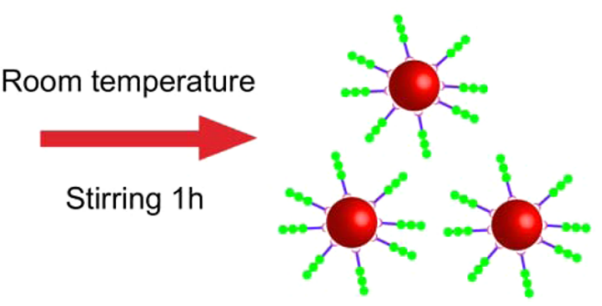

Functional colloidal gold nanoparticles

Figure 1. Schematic illustration of the MDP design for one-step synthesis and surface modification of AuNPs. (a) Chemical sketch of a proof-ofconcept MDP, RGDSGGGGKDopa-Am, where Dopa and Lys serve as synthesis and stabilization units, Gly functions as a steric linker to Arg-GlyAsp-Ser, an integrin-binding peptide sequence. (b) Proposed synthesis and surface modification (capping) of AuNPs with the peptides.

In the present study, we describe design of multidomain peptides (MDPs) for single-step, size-controlled synthesis of biofunctionalized AuNPs (Figure 1). Synthesis of AuNPs with MDPs relies on 3,4-dihydroxy-L-phenylalanine (Dopa) residues, a mussel-inspired residue known for its reductive role to facilitate rapid curing of the mussel glue under water. ${ }^{20} \mathrm{We}$ showed that Dopa couples its oxidation to the reduction of $\mathrm{Au}$ (III) ions, thereby leading to the formation of AuNPs. Furthermore, Dopa-mediated MDP design enables concerted reduction, stabilization and functionalization all by the same molecule at one-pot, whereby no additional reagent or reaction is needed. MDPs also provide geometrically flexible space for the presentation of the biofunctional ligand to the outer environment. In contrast to the existing methods, inherent biocompatibility of the peptide provides a greener route toward the synthesis of broad-range $(\sim 2-15 \mathrm{~nm}$ in diameter) biofunctional nanoparticles. Moreover, this strategy is free of inefficiencies that might arise during the ligand exchange reaction. As a result, these AuNPs exhibit remarkable stability in high ionic strength. As proof of this concept, we synthesized AuNPs functionalized with a targeting moiety, Arg-Gly-Asp peptide, which is known to bind to integrin $\alpha_{\mathrm{v}} \beta_{3}$, upregulated on cancer cell surface. ${ }^{21}$ Synthesized MDP-capped AuNPs were exposed to MCF7 cells, and uptake was confirmed by transmission electron microscopy (TEM) and inductively coupled plasma mass spectrometry (ICP-MS) analyses. Overall, the strategy here provides a practical and toxicity-free alternative to the currently established methods for preparation of functionalized AuNPs.

\section{EXPERIMENTAL SECTION}

2.1. Materials. All chemicals and materials used in this study were analytical grade and purchased from Invitrogen, Thermo-Fisher, Merck, Alfa Aesar, ABSR, Millipore, and Sigma-Aldrich.

2.2. Synthesis and Characterization of MDPs. Peptide synthesis was achieved using solid-phase peptide synthesis with 9fluorenylmethoxycarbonyl (Fmoc) chemistry. Rink amide MBHA resin was used as the solid platform. At each coupling step, Fmoc at $\mathrm{N}_{\alpha}$ was removed with $20 \%$ piperidine/dimethylformamide (DMF) solution in $20 \mathrm{~min}$. For activation of carboxylate groups, 2 equiv of amino acids were mixed with 1.95 equiv of $N, N, N^{\prime}, N^{\prime}$-Tetramethyl-O(1H-benzotriazol-1-yl)uronium hexafluorophosphate (HBTU) and 3 equiv of $N, N$-Diisopropylethylamine (DIAE) for 1 equiv of resin. After each coupling step, $10 \%$ acetic anhydride/DMF solution was used to permanently acetylate the unreacted amine groups. A cleavage cocktail containing 95\% trifluoroacetic acid (TFA), 2.5\% water, and $2.5 \%$ triisopropylsilane (TIS) was used to remove all the protecting groups at the end of coupling steps. Excess TFA removal was achieved by rotary evaporation followed by precipitation in diethyl ether at $-20{ }^{\circ} \mathrm{C}$ overnight. The precipitate was then dissolved in ultrapure water, frozen at $-80{ }^{\circ} \mathrm{C}$, and lyophilized for 1 week. Residual TFA was removed with dilute $\mathrm{HCl}$ treatment two times. Other small impurities were removed by dialysis using cellulose ester membrane with a molecular weight cutoff of 100-500 Da. Synthesized peptides were characterized using Agilent 6530 quadrupole time-of-flight (Q-TOF) mass spectrometry with electrospray ionization (ESI) source equipped with a reverse-phase analytical HPLC (Figure S1, SI). Peptide batches were always stored as lyophilized powders at $-20{ }^{\circ} \mathrm{C}$. For each experiment, freshly dissolved aqueous peptide solutions were prepared. The $\mathrm{pH}$ of the solution was adjusted using $1 \mathrm{M} \mathrm{HCl}_{(\mathrm{aq})}$ and $2 \mathrm{M}$ $\mathrm{NaOH}_{(a q)}$.

2.3. Characterization of AuNPs. For the characterization of the AuNPs, the solution was purified by centrifugal filtering using 
(a)

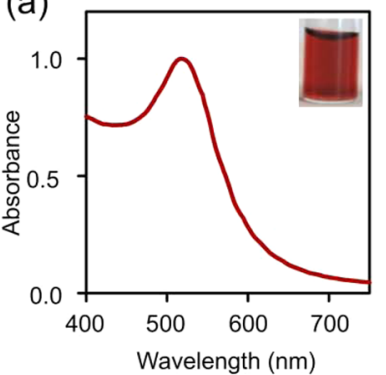

(d)

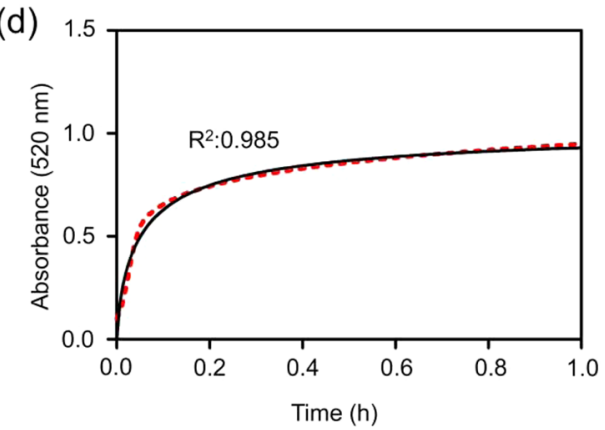

(b) 30

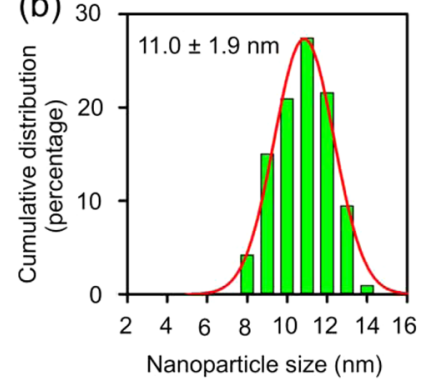

(c)

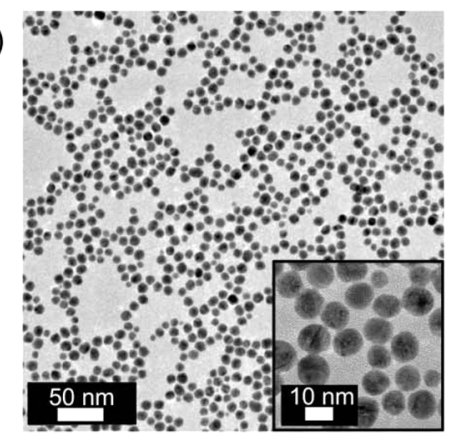

(e)

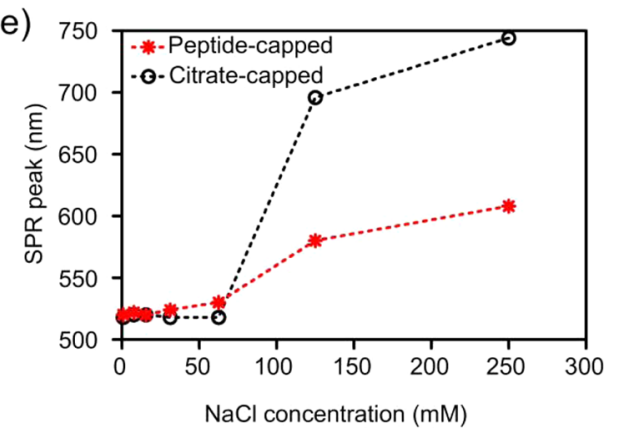

Figure 2. Synthesis, kinetics and colloidal stability of AuNPs. (a) UV-vis spectrum of the peptide-gold solution mixture at $1 \mathrm{~h}$. The inset shows the reaction tube. Solution develops wine red color in $1 \mathrm{~h}$, a typical indicative of AuNPs. (b) Particle size distribution and (c) transmission electron micrographs of AuNPs. (d) Kinetics of nanoparticle formation monitored by the light absorption of surface plasmons at $518 \mathrm{~nm}$. (e) Colloidal stability of MDP-capped AuNPs as compared to citrate-capped AuNPs with the same average size. (MDP: $0.6 \mathrm{mM} ; \mathrm{H}\left[\mathrm{AuCl}{ }_{4}\right]: 19.2 \mathrm{mM}$; $[\mathrm{MDP}]$ : $[\mathrm{Au}(\mathrm{III})]=1: 32)$.

Millipore Amicon Ultra-4 centrifugal filter units at $5000 \mathrm{rpm}$ for $5 \mathrm{~min}$ with 10 repeats, in each of which $\sim 2 / 3$ of continuous water phase was removed and then replaced with fresh ultrapure water. Final pure AuNP solution was stored at room temperature for months without observing any macroscopic destabilization. Unless otherwise mentioned, all characterizations of AuNPs were carried out in ultrapure water. Spectral and kinetic analyses of AuNPs were performed with SpectraMax M5Multi-Mode Microplate Reader. A spectral range of $250-750 \mathrm{~nm}$ was scanned with $2 \mathrm{~nm}$ increments. Kinetics of the synthesis was monitored by recording spectral absorbance at $518 \mathrm{~nm}$ (around the center of surface plasmon resonance (SPR)) in $3 \mathrm{~min}$ intervals for a period of $1 \mathrm{~h}$. A magnetic stirrer in the spectrophotometer enabled homogeneous sample distribution throughout the readings. Recording was started immediately after $\mathrm{pH}$ adjustment to $\sim 10$. Transmission electron microscopy (TEM) images of AuNPs were obtained with FEI Tecnai G2 F30 series at 300 $\mathrm{kV}$. The samples were prepared by dropping AuNP solution on a carbon-coated copper grid followed by air-drying. Core size distribution of AuNPs was determined based on the TEM images. Hydrodynamic size distribution and zeta potential of AuNPs were measured using a Malvern Zeta Sizer NanoZS. Dynamic light scattering (DLS) was carried out with AuNPs dispersed in ultrapure water following the purification step described above. Prior to the DLS measurement, the samples were vortexed and treated with ultrasound sonication and then equilibrated at rest for $5 \mathrm{~min}$. For the automated zeta size measurements, AuNPs dispersed in ultrapure water were titrated with $0.01 \mathrm{M} \mathrm{HCl}$ and $0.01 \mathrm{M} \mathrm{NaOH}$. A magnetic stirrer enabled continuous stirring for equilibration. All results are the averages of at least three independent measurements.

2.4. Colloidal Stability of AuNPs. Colloidal stability of AuNPs was investigated by monitoring the impact of ionic strength on the SPR of AuNPs. Citrate-capped AuNPs was used as the negative control. Both citrate- and peptide-capped AuNPs in the same molar concentrations and the same average core sizes $(11 \mathrm{~nm})$ were incubated in a series of increasing sodium chloride $(\mathrm{NaCl})$ concentrations $(0-250 \mathrm{mM})$. The mixtures were allowed for stabilization for $1 \mathrm{~h}$. Then, the SPR centers were determined by scanning in the range of $250-750 \mathrm{~nm}$ with $2 \mathrm{~nm}$ increments.

2.5. Ligand Density on Gold Nanoparticles. Bound-peptides on AuNPs were determined using Pierce BCA Protein Assay Kit. Samples were prepared according to the recommendation of the manufacturer. Briefly, AuNPs were purified with centrifugal filtration as explained above in order to remove any unbound peptide residue from the solution. Then, peptides bound on AuNPs were reacted with $\mathrm{Cu}^{2+}$ to produce spectrophotometrically quantifiable blue-violet color, which is indicative of $\mathrm{Cu}^{1+}$ (biuret reaction). To intensify this signal, we coordinated $\mathrm{Cu}^{1+}$ ions with bicinchoninic acid and recorded the resulting absorbance at $562 \mathrm{~nm}^{22}$ Standard curves for peptides were prepared using unreacted peptide solutions.

2.6. In Vitro Characterization of AuNP Uptake. MCF7 cells were cultured in Dulbecco's modified Eagle's medium (DMEM) supplemented with $10 \%$ fetal bovine serum (FBS) and $1 \%$ penicillin/ streptomycin in standard cell culture conditions $\left(37^{\circ} \mathrm{C}, 5 \% \mathrm{CO}_{2}\right.$, and $95 \%$ humidity). Prior to the uptake assay, cytotoxicity of MDP-capped AuNPs was investigated with a dose response colorimetric cellular viability (MTT) assay. MCF7 cells were incubated with serially increasing concentrations of $11 \mathrm{~nm}$ MDP-capped AuNPs (12.5, 25, and $50 \mu \mathrm{g} \mathrm{mL}^{-1}$ ). After $3 \mathrm{~h}$ of incubation, MDP-capped AuNPs did not elicit any significant loss in cell viability (Figure S2, SI). This result designated the biocompatibility of the MDP-capped AuNPs within the concentration range of $50 \mu \mathrm{g} \mathrm{mL}^{-1}$. To determine the uptake pathway of the engineered AuNPs, we inhibited three major endocytosis pathways. Then, the resulting amount of the AuNP uptake was compared. For this, MCF7 cells were grown on 96-well plates until they reached $80-90 \%$ confluency. Prior to adding engineered AuNPs, cells were incubated with one of following inhibitors prepared in serum-free DMEM for $1 \mathrm{~h}$ : amiloride $(5 \mathrm{mM})$, chlorpromazine $(5 \mu \mathrm{g}$ $\left.\mathrm{mL}^{-1}\right)$, or Filipin III $(50 \mathrm{nM})$. After $1 \mathrm{~h}$, the inhibitors were removed, and $25 \mu \mathrm{g} \mathrm{mL}^{-1}$ AuNPs were introduced to cells in serum-free fresh media supplemented with the inhibitors. For the uptake experiments, serum-free DMEM containing $1 \%$ penicilin/streptomycin was used in order to avoid nonspecific interactions. MCF7 cells were incubated with the nanoparticles for $4 \mathrm{~h}$. Uptake was then terminated by 
removing the medium and thoroughly washing the cells with phosphate buffered saline (PBS, $\mathrm{pH}$ 7.4). The samples were digested using aqua regia $\left(\mathrm{HCl}: \mathrm{HNO}_{3} 3: 1\right)$ overnight. These lysates were then transferred to $2 \%$ nitric acid. Gold ions in the lysates were quantified through inductively coupled plasma-mass spectrometry (ICP-MS, Thermo X Series II). A standard curve was prepared by dissolving and serially diluting $1 \mathrm{ppm}$ of $\mathrm{H}\left[\mathrm{AuCl}_{4}\right]$ in $2 \%$ nitric acid to obtain 12.5 , $6.25,3.125,1.56$, and $0.78 \mathrm{ppb}$ standard gold concentrations.

2.7. Statistical Analysis. All experiments were analyzed in triplicates or quadruplicates, with at least two independent repeats. Error bars represent standard error of the mean (SEM). Statistical significance was determined using one-way ANOVA with a confidence interval of $P<0.05$.

\section{RESULTS AND DISCUSSION}

A short multidomain peptide (MDP) was designed and synthesized to concertedly carry out three separate tasks required for the synthesis and functionalization of AuNPs (Figure 1a): (1) Mussel-inspired Dopa has a catechol side chain, which has suitable reduction potential $\left(E^{0}\right.$-Dopa $=-745$ $\mathrm{mV})$ to reduce gold ion into gold atom $\left(E^{0}-\mathrm{Au}(\mathrm{III})=+1.52 \mathrm{~V}\right)$ at $\mathrm{pH} 7 .{ }^{18,23,24}$ In addition, the catechol could bind to various metals, oxides and metal ions. ${ }^{20}$ In this regard, Dopa was chosen to serve as both reducing and stabilizing agents. Lysine residues assisted further stabilization of AuNPs. (2) Linker domain aimed to form a steric interface between AuNP binding domain and the following functionalization domain. This domain can also be considered as a secondary functionalization domain for multitasking complex applications. For example, glycine can be replaced with positively charged residues, such as histidine, to serve as carriers for nucleotides in gene delivery applications or as endosome-escaping proton sponges. ${ }^{25,26}$ (3) For active targeting in biological environment, we further included an integrin-targeting domain, comprised of arginineglycine-aspartate. AuNPs were typically synthesized by the route outlined in Figure 1b. MDP solution $(1 \mathrm{~mL}, 0.6 \mathrm{mM}, \mathrm{pH}$ 23) was allowed to react with an equal volume of $\mathrm{H}\left[\mathrm{AuCl}_{4}\right]$ solution $(19.2 \mathrm{mM})([\mathrm{MDP}]:[\mathrm{Au}(\mathrm{III})]=1: 32)$ at room temperature. Immediately after the $\mathrm{Au}^{3+}$ and MDP solutions were mixed, the container tube was thoroughly vortexed for 10 s. Then, $\mathrm{pH}$ of this solution was elevated to $\sim 10$ by $2 \mathrm{M}$ $\mathrm{NaOH}_{(\mathrm{aq})}$, vortexed immediately and vigorously for $10 \mathrm{~s}$, and incubated at room temperature for $1 \mathrm{~h}$ by continuous stirring. $\mathrm{pH}$ elevation triggered spontaneous oxidation of catechol, which was coupled to the reduction of $\mathrm{Au}^{3+27}$ This redox coupling was demonstrated by the spectral monitoring of the reaction. Immediately after the $\mathrm{Au}^{3+}$ solution was mixed with the MDP solution, a bathochromic shift was observed from 280 $\mathrm{nm}$ (attributable to catechol) to around $350 \mathrm{~nm}$ (attributable to quinone). ${ }^{28}$ Upon $\mathrm{pH}$ elevation, this quinone peak started to diminish along with a global increase in the visible range of the spectrum. At the end of $1 \mathrm{~h}$, characteristic SPR peak became evident at $518 \mathrm{~nm}$ (Figure 2a). This was also detectable by eye as the yellow-gold solution turned into wine-red in $1 \mathrm{~h}$ (Figure 2a, inset). To confirm the formation of nanoparticles, we investigated samples using TEM, which showed spherical nanoparticle formation with an average core size of $11.0 \pm 1.9$ $\mathrm{nm}$ (Figure 2b,c). Energy dispersive X-ray (EDX) spectrum verified the presence of AuNPs (Figure S3, SI). Selected-area electron diffraction (SAED) patterns finally revealed specific lattices pertaining to polycrystalline AuNPs (Figure S3, inset, SI). In water, the hydrodynamic size of these AuNPs was found to be $14.5 \pm 0.8 \mathrm{~nm}$. Compared to the core nanoparticle size (obtained from TEM micrographs), higher hydrodynamic size obtained from DLS measurements is attributable to the solvation effect and the presence of the peptide cap. DLS measurements further confirmed that there was no aggregation in the solution, at least over the time-scale of the measurements. The unique wine-red color of the solution remained unchanged for over a year, a further indication of the nanoparticle stability. Zeta potentials of MDP-AuNPs in water were measured over a $\mathrm{pH}$ range of 2.5-11.5 (Figure S4, SI). Nanoparticles were slightly positive and neutral at acidic and neutral $\mathrm{pH}$ values, whereas they were negatively charged at basic $\mathrm{pH}$. This amphoteric behavior was attributed to the peptide capping, of which $\mathrm{pH}$-dependent net charge affects the surface charge of the nanoparticle.

Kinetics of AuNP formation was monitored by time-wise tracking of the surface plasmon resonance at $518 \mathrm{~nm}$. Nanoparticle formation started within seconds after the initiation of the reaction, that is, the $\mathrm{pH}$ elevation, and reached equilibrium at room temperature within $1 \mathrm{~h}$ (Figure 2d). Compared to the existing synthesis techniques, which usually require boiling of the gold solution to prepare monomeric precursors for nucleation, using MDPs enabled a much milder route in a comparatively faster reaction scheme. Surface functionalization of AuNPs with MDPs was demonstrated by the colloidal stability of the nanoparticles against the ionic strength (Figure 2e). MDP-capped AuNP dispersions were relatively stable in up to $100 \mathrm{mM} \mathrm{NaCl}$ salt concentration. On the other hand, citrate-capped AuNPs started to coagulate after $62 \mathrm{mM} \mathrm{NaCl}$ with further red shifting in SPR bands with increasing $\mathrm{NaCl}$ concentrations. As a result, it was concluded that MDP functionalization, ascribed to the strong binding capacity of Dopa to metals, provided steric stability to AuNPs. ${ }^{20}$ Mechanism of gold nanoparticle formation was analyzed by UV-vis spectroscopy (Figure S5, SI). Before the addition of gold salt into the MDP solution at $\mathrm{pH} 5$, Dopa adsorption peak at $280 \mathrm{~nm}$ was detected. When the $\mathrm{pH}$ of the peptide solution was increased to 10 , a broad shoulder ranging from 300 to $500 \mathrm{~nm}$ indicating the oxidized quinone formation was observed. Aqueous $\mathrm{H}\left[\mathrm{AuCl}_{4}\right]$ solution shows an intense band around $320 \mathrm{~nm}$ due to charge transfer between the metal and chloride ions. ${ }^{29}$ As soon as aqueous $\mathrm{H}\left[\mathrm{AuCl}_{4}\right]$ was mixed with MDP solution at $\mathrm{pH} 10$, this peak vanished corresponding to the complete reduction of $\mathrm{Au}$ (III). This is because of the high reduction potential of Dopa, which gave electrons to $\mathrm{Au}(\mathrm{III})$ ions to instantly generate gold nanoparticles and converted into quinones. ${ }^{18,24}$ Within $1 \mathrm{~h}$, the color of the solution almost completely turned wine-red along with the maximum SPR peak value at $518 \mathrm{~nm}$, indicating that AuNP formation has reached into equilibrium.

The ability to synthesize AuNPs at varying sizes with a narrow distribution is highly important, as the size dictates the ultimate colloidal, physicochemical, and optoelectronic properties of the nanoparticles. Synthesis of size-controlled AuNPs was carried out by mixing serially diluted $\mathrm{H}\left[\mathrm{AuCl}_{4}\right]$ solutions (from 76.8 to $1.2 \mathrm{mM}$ with a dilution factor of 2) with MDP (0.6 mM, pH $\sim 3$ ) at equal volumes. As described previously, the reaction was initiated by $\mathrm{pH}$ elevation. We observed that color of the solutions varied from bright orange (1:128 peptide/gold molar ratio) to wine-red (1:32) and to light-pink $(1: 2)$, which represented the unique characteristics of nanoparticles in the order of increasing core size (Figure 3a). Concomitant with the color change, SPR bands of synthesized AuNPs shifted to longer wavelengths with decreasing amounts of gold salt ratio in the initial solution (Figure $3 \mathrm{~b}$ ). Indeed, core 
(a)

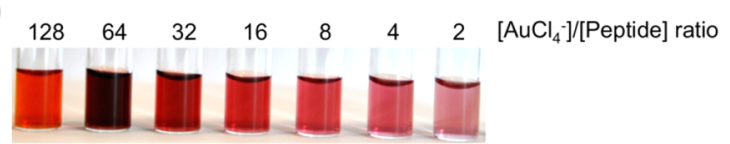

(b)

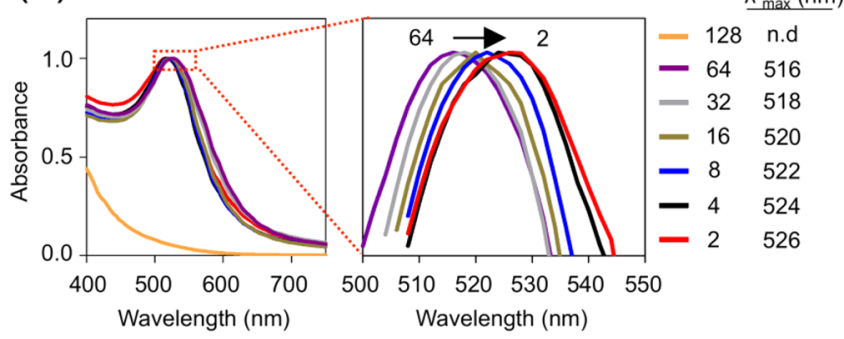

Figure 3. Size-controlled one-pot synthesis of MDP functionalized AuNPs. (a) Size-dependent color development in the reaction tubes. (b) Normalized UV-vis spectra of MDP-capped AuNPs showing a consistent red-shift as the $[\mathrm{Au}(\mathrm{III})]:[\mathrm{MDP}]$ ratio decreases.

size analysis by TEM revealed that particle size increases progressively with decreasing amounts of gold salt in the initial solution (Figure S6, SI). The average diameters extracted from TEM images along with their Au-to-peptide ratios are listed in Table 1 . The size distributions were concordant with the results

Table 1. Size and Surface Characteristics of MDP-Capped AuNPs: Core Size, Estimated Number of Gold Atoms per Nanoparticles, and the Number of Peptide Ligands on Each Nanoparticle

$\begin{array}{cccc}\begin{array}{c}{[\mathrm{Au}(\mathrm{III})]^{a}} \\ {[\mathrm{MDP}]^{a}}\end{array} & \begin{array}{c}\text { core size } \\ (\mathrm{nm})^{b}\end{array} & \begin{array}{c}N^{c} \text { Au atoms/ } \\ \mathrm{NP}\end{array} & \begin{array}{c}\text { peptide ligand/ } \\ \mathrm{NP}^{d}\end{array} \\ 128 & 2.3 \pm 0.7 & 376 & \text { na } \\ 64 & 7.0 \pm 1.3 & 10597 & 191 \\ 32 & 11.0 \pm 1.9 & 41123 & 627 \\ 16 & 12.8 \pm 2.1 & 64642 & 755 \\ 8 & 14.3 \pm 3.1 & 90726 & 1741 \\ 4 & 15.5 \pm 2.9 & 115053 & 2115 \\ 2 & 15.0 \pm 2.2 & 105951 & 2150\end{array}$

${ }^{a}$ Molar ratios of MDP solution and gold solution used to synthesize various sized MDP-capped AuNPs. ${ }^{b}$ Core size was determined by $>300$ particle counts in each group from TEM images. ${ }^{c}$ The average number $(N)$ of gold atoms per nanoparticle was calculated assuming that AuNPs are spherical with a uniform fcc structure with the following equation. ${ }^{39} N=30.89602 D .^{3}{ }^{d}$ Ligand number per nanoparticle was estimated by the colorimetric staining of peptides.

previously reported by using catechol chemistry to synthesize AuNPs. ${ }^{23}$ Using this chemistry, we were able to synthesize MDP-capped AuNPs with controlled sizes ranging from 2.3 to $15.5 \mathrm{~nm}$ in diameter. Further, size distribution of MDP-capped AuNPs were about $\sim 20 \%$ of their average core sizes, which is a significant improvement compared to the particle size distribution of AuNPs synthesized with previously reported one-pot preparation methods. ${ }^{19,23}$ Because of their small size $(2.3 \mathrm{~nm})$, particles with 1:128 molar ratio did not exhibit SPR band. ${ }^{11,30}$ We conclude that the ability of the multidomain peptide to separate and concert nucleation and growth phases of nanoparticle formation enabled fine-tuned synthesis with a narrow size distribution.

To show the versatility of the multidomain peptide approach, we used additional peptides with altered or cleaved sequences to synthesize engineered AuNPs in one pot (Figure S7a, SI). AuNPs syntheses with the same one-pot technique were accomplished within $1 \mathrm{~h}$ (Figure S7b, SI). In terms of colloidal stability, all MDP-capped AuNPs showed higher stability than citrate-capped AuNPs in increasing ionic strength conditions (Figure S7c, SI). TEM micrographs demonstrated P2-AuNPs from 2.3 to $26.1 \mathrm{~nm}$ with an average size distribution of $22.5 \%$. P3-AuNPs had a smaller size range from 9.8 to $13.3 \mathrm{~nm}$ with an average size distribution of $17.8 \%$. Due to the shorter peptide sequence of $\mathrm{P} 3$, compared to $\mathrm{P} 1$ and $\mathrm{P} 2$, nanoparticles smaller than $10 \mathrm{~nm}$ were prone to aggregation owing to the decreased steric shielding in the presence of high ionic strength.

The uptake of MDP-capped AuNPs was analyzed by incubating monolayers of MCF7 cells with synthesized gold nanoparticles. MCF7 cells have previously been treated with RGD-functionalized targeting agents, because $\alpha_{\mathrm{v}} \beta_{3}$ integrins exhibited on the cell surface recognizes this short peptide sequence. ${ }^{31-33}$ Protein agglomeration on nanoparticle surfaces introduces new epitopes for cellular uptake and therefore enhances endocytosis. ${ }^{34}$ To prevent such nonspecific enhancement of endocytosis, we performed uptake experiments in serum-free media. TEM micrographs revealed that nanoparticles were internalized by MCF7 cells (Figure S8, SI). During endocytosis, cell membranes with receptors "wrap" around a particle coated with matching ligands. ${ }^{35}$ Eleven $\mathrm{nm}$ MDP-AuNPs formed clusters in order to enter the cell. This is compatible with the models developed to understand the dynamics of endocytosis such that a single NP smaller than 50 $\mathrm{nm}$ does not produce enough free energy to completely wrap the membrane around the NPs. ${ }^{35}$ Hence, the nanoparticles were mainly clustered in order to be uptaken by the cells. Understanding the mechanisms of internalization is critical to design nanoparticles precisely for specific purposes. To obtain a deep understanding of MDP-capped AuNP uptake, we analyzed their internalization mechanisms and pathways in MCF7 cells. Although internalization mechanisms are really diverse, they generally are classified into three main groups: clathrin mediated, lipid raft/caveolae mediated, and macropinocytosis/phagocytosis. ${ }^{36}$ Chemical inhibition of these pathways are regularly used in biology. ${ }^{37}$ Amiloride, which blocks macropinocytosis; chlorpromazine, which prevents the formation of clathrin coated pits; and filipin III, which inhibits caveole mediated uptake, were incubated with the cells for 1 h. ${ }^{38}$ Then solutions containing MDP-capped AuNPs $(25 \mu \mathrm{g}$ $\mathrm{mL}^{-1}$ ) and each inhibitor were added to the culture media and incubated for an additional $4 \mathrm{~h}$. The resulting cells were lysed and subjected to ICP-MS for the detection of gold content. Cells that were not exposed to nanoparticles were used as negative control and cells that were not exposed to inhibitors were used as positive control. The quantitative gold analysis revealed that MDP-capped AuNPs enter into MCF7 cells by several pathways (Figure 4). Amiloride and chlorpromazine significantly inhibited 68 and $39 \%$ of the nanoparticles uptaken by cells, respectively. This indicated the role of macropinocytosis and clathrin-mediated endocytosis (CME) in MDP-capped AuNP uptake. Filipin III, on the other hand, had no effect on uptake suggesting that caveole-mediated uptake might not be involved in endocytosis of MDP-capped AuNPs. Collectively, these results supported the strong involvement of CME and macropinocytosis in the uptake of MDP-capped AuNPs by MCF7 cells. 


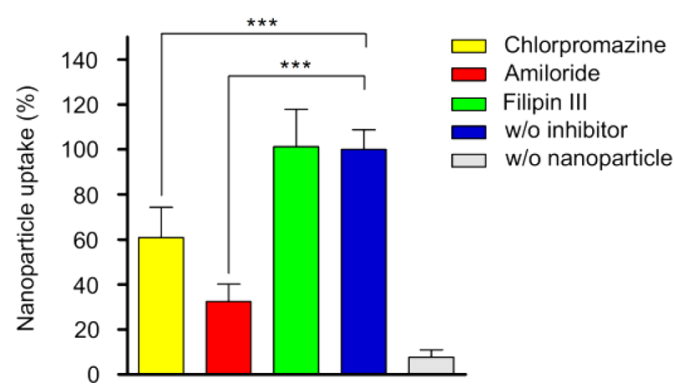

Figure 4. Cellular uptake of MDP-capped AuNPs. ICP-MS analysis of MCF7 cells treated with chemical inhibitors of endocytosis and incubated with $25 \mu \mathrm{g} \mathrm{mL}^{-1}$ of MDP-capped AuNPs. Cell numbers were normalized to untreated MCF7 cells. Error bars indicate standard error of the mean $(n=4)$. Statistical significance was determined using one-way ANOVA with Tukey's Multiple Comparison Test, $* * * P<$ 0.0001 .

\section{CONCLUSION}

Here, we describe a simple, robust, and greener way to prepare engineered gold nanoparticles (AuNPs). The strategy introduced here circumvents the major obstacles of the conventional methods with potentially toxic byproducts, extended synthesis times, engineering efficiency, and poor size control. Musselinspired Dopa modification of MDPs could devise synthesis, capping, and functionalization of AuNPs without requiring additional stabilizer, strong reducing agent, or toxic surfactant in a single step. Engineered AuNPs had long-term stability and high ionic strength provided by the peptide capping. Controlled synthesis of AuNPs with MDPs enabled the stable formation of AuNPs in the range of $2-15 \mathrm{~nm}$. It is still unclear why there is an inverse relationship between particle core size and the relative gold precursor amount in the solution. A similar result has previously been reported using catechol chemistry to synthesize AuNPs. ${ }^{23}$ This observation deserves a more careful future investigation to better understand routes for nanoparticle synthesis and stabilization. Nonetheless, the resulting nanoparticle size range is within biomedical values, indicating that the AuNPs could potentially be used as drug and gene carriers, in photothermal therapy, and in screening applications. MDPcapped AuNPs showed excellent biocompatibility along with targeted cellular uptake through CME and macropinocytosis. One can optimize the design of AuNPs for various applications by modularly modifying MDP sequences.

\section{ASSOCIATED CONTENT}

\section{S Supporting Information}

LC-MS analysis and UV-vis spectra of the MDP; EDX spectra, SAED analysis, TEM images, and synthesis mechanism analysis of MDP-capped AuNPs; multidomain peptide approach with varying peptide sequences; and TEM analysis of MDP-AuNP cellular uptake. The Supporting Information is available free of charge on the ACS Publications website at DOI: 10.1021/ acsami.5b00093.

\section{AUTHOR INFORMATION}

\section{Corresponding Authors}

*E-mail: moguler@unam.bilkent.edu.tr.

*E-mail: atekinay@unam.bilkent.edu.tr.

\section{Author Contributions}

${ }^{\dagger}$ These authors contributed equally.The manuscript was written through contributions of all authors. All authors have given approval to the final version of the manuscript.

\section{Notes}

The authors declare no competing financial interest.

\section{ACKNOWLEDGMENTS}

This work was partially funded by The Scientific and Technological Research Council of Turkey (TUBITAK; Grant nos. 113M900 and 213M001). H.C. acknowledges support from TUBITAK-BIDEB fellowship. A.B.T. and M.O.G. acknowledge support from the Turkish Academy of Sciences Distinguished Young Scientist Award (TUBA-GEBIP). The authors would like to thank M. Guler for assistance with TEM imaging, Dr. G. Celik for assistance with ICP-MS analysis, and Z. Erdogan for assistance with LC-MS analysis.

\section{REFERENCES}

(1) Webb, J. A.; Bardhan, R. Emerging Advances in Nanomedicine with Engineered Gold Nanostructures. Nanoscale 2014, 6, 2502-2530.

(2) Brown, S. D.; Nativo, P.; Smith, J.-A.; Stirling, D.; Edwards, P. R.; Venugopal, B.; Flint, D. J.; Plumb, J. A.; Graham, D.; Wheate, N. J. Gold Nanoparticles for the Improved Anticancer Drug Delivery of the Active Component of Oxaliplatin. J. Am. Chem. Soc. 2010, 132, 46784684.

(3) Muroski, M. E.; Kogot, J. M.; Strouse, G. F. Bimodal Gold Nanoparticle Therapeutics for Manipulating Exogenous and Endogenous Protein Levels in Mammalian Cells. J. Am. Chem. Soc. 2012, 134, 19722-19730.

(4) Kennedy, L. C.; Bickford, L. R.; Lewinski, N. A.; Coughlin, A. J.; Hu, Y.; Day, E. S.; West, J. L.; Drezek, R. A. A New Era for Cancer Treatment: Gold-Nanoparticle-Mediated Thermal Therapies. Small 2011, 7, 169-183.

(5) Huang, X.; El-Sayed, I. H.; Qian, W.; El-Sayed, M. A. Cancer Cell Imaging and Photothermal Therapy in the Near-Infrared Region by Using Gold Nanorods. J. Am. Chem. Soc. 2006, 128, 2115-2120.

(6) Curry, T.; Kopelman, R.; Shilo, M.; Popovtzer, R. Multifunctional Theranostic Gold Nanoparticles for Targeted CT Imaging and Photothermal Therapy. Contrast Media Mol. Imaging 2014, 9, 53-61.

(7) Valentini, P.; Fiammengo, R.; Sabella, S.; Gariboldi, M.; Maiorano, G.; Cingolani, R.; Pompa, P. P. Gold-Nanoparticle-Based Colorimetric Discrimination of Cancer-Related Point Mutations with Picomolar Sensitivity. ACS Nano 2013, 7, 5530-5538.

(8) Libutti, S. K.; Paciotti, G. F.; Myer, L.; Haynes, R.; Gannon, W.; Walker, M.; Seidel, G.; Byrnes, A.; Yuldasheva, N.; Tamarkin, L. Results of a Completed Phase I Clinical Trial of CYT-6091: A Pegylated Colloidal Gold-TNF Nanomedicine. J. Clin. Oncol. 2009, $27,3586$.

(9) Turkevich, J.; Stevenson, P. C.; Hillier, J. A Study of the Nucleation and Growth Processes in the Synthesis of Colloidal Gold. Discuss. Faraday Soc. 1951, 11, 55-75.

(10) Brust, M.; Walker, M.; Bethell, D.; Schiffrin, D. J.; Whyman, R. Synthesis of Thiol-Derivatised Gold Nanoparticles in a Two-Phase Liquid-Liquid System. J. Chem. Soc., Chem. Commun. 1994, 801-802.

(11) Daniel, M.-C.; Astruc, D. Gold Nanoparticles: Assembly, Supramolecular Chemistry, Quantum-Size-Related Properties, and Applications toward Biology, Catalysis, and Nanotechnology. Chem. Rev. 2003, 104, 293-346.

(12) Yonezawa, T.; Yasui, K.; Kimizuka, N. Controlled Formation of Smaller Gold Nanoparticles by the Use of Four-Chained Disulfide Stabilizer. Langmuir 2000, 17, 271-273.

(13) Dewi, M. R.; Laufersky, G.; Nann, T. A. Highly Efficient Ligand Exchange Reaction on Gold Nanoparticles: Preserving Their Size, Shape and Colloidal Stability. RSC Adv. 2014, 4, 34217-34220.

(14) Soenen, S. J.; Manshian, B.; Montenegro, J. M.; Amin, F.; Meermann, B.; Thiron, T.; Cornelissen, M.; Vanhaecke, F.; Doak, S.; 
Parak, W. J.; De Smedt, S.; Braeckmans, K. Cytotoxic Effects of Gold Nanoparticles: A Multiparametric Study. ACS Nano 2012, 6, 57675783.

(15) Krpetic, Z.; Nativo, P.; Porta, F.; Brust, M. A Multidentate Peptide for Stabilization and Facile Bioconjugation of Gold Nanoparticles. Bioconjugate Chem. 2009, 20, 619-624.

(16) Arosio, D.; Manzoni, L.; Araldi, E. M. V.; Scolastico, C. Cyclic RGD Functionalized Gold Nanoparticles for Tumor Targeting. Bioconjugate Chem. 2011, 22, 664-672.

(17) Scari, G.; Porta, F.; Fascio, U.; Avvakumova, S.; Dal Santo, V.; De Simone, M.; Saviano, M.; Leone, M.; Del Gatto, A.; Pedone, C.; Zaccaro, L. Gold Nanoparticles Capped by a GC-Containing Peptide Functionalized with an RGD Motif for Integrin Targeting. Bioconjugate Chem. 2012, 23, 340-349.

(18) Lee, Y.; Park, T. G. Facile Fabrication of Branched Gold Nanoparticles by Reductive Hydroxyphenol Derivatives. Langmuir 2011, 27, 2965-2971.

(19) Huang, X.; Wu, H.; Liao, X.; Shi, B. One-Step, Size-Controlled Synthesis of Gold Nanoparticles at Room Temperature Using Plant Tannin. Green Chem. 2010, 12, 395-399.

(20) Lee, H.; Dellatore, S. M.; Miller, W. M.; Messersmith, P. B. Mussel-Inspired Surface Chemistry for Multifunctional Coatings. Science 2007, 318, 426-430.

(21) Pierschbacher, M. D.; Ruoslahti, E. Cell Attachment Activity of Fibronectin can be Duplicated by Small Synthetic Fragments of the Molecule. Nature 1984, 309, 30-33.

(22) Smith, P. K.; Krohn, R. I.; Hermanson, G. T.; Mallia, A. K.; Gartner, F. H.; Provenzano, M. D.; Fujimoto, E. K.; Goeke, N. M.; Olson, B. J.; Klenk, D. C. Measurement of Protein Using Bicinchoninic Acid. Anal. Biochem. 1985, 150, 76-85.

(23) Black, K. C. L.; Liu, Z.; Messersmith, P. B. Catechol Redox Induced Formation of Metal Core-Polymer Shell Nanoparticles. Chem. Mater. 2011, 23, 1130-1135.

(24) Eslami, M.; Zare, H. R.; Namazian, M. Thermodynamic Parameters of Electrochemical Oxidation of 1-DOPA: Experimental and Theoretical Studies. J. Phys. Chem. B 2012, 116, 12552-12557.

(25) Shi, J.; Schellinger, J. G.; Johnson, R. N.; Choi, J. L.; Chou, B.; Anghel, E. L.; Pun, S. H. Influence of Histidine Incorporation on Buffer Capacity and Gene Transfection Efficiency of HPMA-cooligolysine Brush Polymers. Biomacromolecules 2013, 14, 1961-1970.

(26) Bennevault-Celton, V.; Urbach, A.; Martin, O.; Pichon, C.; Guégan, P.; Midoux, P. Supramolecular Assemblies of Histidinylated $\alpha$-Cyclodextrin in the Presence of DNA Scaffold during CDplexes Formation. Bioconjugate Chem. 2011, 22, 2404-2414.

(27) Ceylan, H.; Urel, M.; Erkal, T. S.; Tekinay, A. B.; Dana, A.; Guler, M. O. Mussel Inspired Dynamic Cross-Linking of Self-Healing Peptide Nanofiber Network. Adv. Funct. Mater. 2013, 23, 2081-2090. (28) Xu, H.; Nishida, J.; Ma, W.; Wu, H.; Kobayashi, M.; Otsuka, H.; Takahara, A. Competition between Oxidation and Coordination in Cross-Linking of Polystyrene Copolymer Containing Catechol Groups. ACS Macro Lett. 2012, 1, 457-460.

(29) Qin, X.; Lu, W.; Chang, G.; Luo, Y.; Asiri, A.; Al-Youbi, A.; Sun, $\mathrm{X}$. Novel Synthesis of Au Nanoparticles Using Fluorescent Carbon Nitride Dots as Photocatalyst. Gold Bull. 2012, 45, 61-67.

(30) Yeh, Y.-C.; Creran, B.; Rotello, V. M. Gold Nanoparticles: Preparation, Properties, and Applications in Bionanotechnology. Nanoscale 2012, 4, 1871-1880.

(31) Kim, J.; Nam, H. Y.; Kim, T.-i.; Kim, P.-H.; Ryu, J.; Yun, C.-O.; Kim, S. W. Active Targeting of RGD-Conjugated Bioreducible Polymer for Delivery of Oncolytic Adenovirus Expressing shRNA Against IL-8 mRNA. Biomaterials 2011, 32, 5158-5166.

(32) Lin, R.-Y.; Dayananda, K.; Chen, T.-J.; Chen, C.-Y.; Liu, G.-C.; Lin, K.-L.; Wang, Y.-M. Targeted RGD Nanoparticles for Highly Sensitive in vivo Integrin Receptor Imaging. Contrast Media Mol. Imaging 2012, 7, 7-18.

(33) Jiang, J.; Yang, S.-J.; Wang, J.-C.; Yang, L.-J.; Xu, Z.-Z.; Yang, T.; Liu, X.-Y.; Zhang, Q. Sequential Treatment of Drug-Resistant Tumors with RGD-Modified Liposomes Containing siRNA or Doxorubicin. Eur. J. Pharm. Biopharm. 2010, 76, 170-178.
(34) Nel, A. E.; Madler, L.; Velegol, D.; Xia, T.; Hoek, E. M. V.; Somasundaran, P.; Klaessig, F.; Castranova, V.; Thompson, M. Understanding Biophysicochemical Interactions at the Nano-Bio Interface. Nat. Mater. 2009, 8, 543-557.

(35) Gao, H.; Shi, W.; Freund, L. B. Mechanics of ReceptorMediated Endocytosis. Proc. Natl. Acad. Sci. U.S.A. 2005, 102, 94699474.

(36) Doherty, G. J.; McMahon, H. T. Mechanisms of Endocytosis. Annu. Rev. Biochem. 2009, 78, 857-902.

(37) Thompson, D. B.; Villasenor, R.; Dorr, B. M.; Zerial, M.; Liu, D. R. Cellular Uptake Mechanisms and Endosomal Trafficking of Supercharged Proteins. Chem. Biol. 2012, 19, 831-843.

(38) Iversen, T.-G.; Skotland, T.; Sandvig, K. Endocytosis and Intracellular Transport of Nanoparticles: Present Knowledge and Need for Future Studies. Nano Today 2011, 6, 176-185.

(39) Liu, X.; Atwater, M.; Wang, J.; Huo, Q. Extinction Coefficient of Gold Nanoparticles with Different Sizes and Different Capping Ligands. Colloids Surf., B 2007, 58, 3-7. 